\title{
IS THERE A FUTURE FOR THE INFORMAL RECYCLING SECTOR IN URBAN CHINA?
}

\author{
Benjamin Steuer ${ }^{1, *}$, Roland Ramusch ${ }^{2}$ and Stefan Salhofer ${ }^{3}$ \\ ${ }^{1}$ Institute of Sinology, University of Vienna, Spitalgasse 2, 1090, Vienna, Austria \\ ${ }^{2}$ European Bank for Reconstruction and Development / EBRD, London, United Kingdom \\ ${ }^{3}$ Institute of Waste Management, University of Natural Resources and Life Sciences, Muthgasse 107, 1190, Vienna, Austria
}

Article Info:
Received:
20 February 2018
Revised:
13 August 2018
Accepted:
17 October 2018
Available online:
9 November 2018
Keywords:
China
Beijing
Informal recycling
Waste picker
Waste management
Circular economy

Article Info:

20 February 2018

Revised:

Accepted:

17 October 2018

9 November 2018

Keywords:

China

nformal recycling

Waste management

Circular economy

\begin{abstract}
This article constitutes a comprehensive overview that summarises first-hand research findings obtained by the authors through scientific engagement with the informal recycling sector (IRS) in mainland China over the past six years. During this research period, especially between 2013 and 2016, we found several indications that the working environment of informal stakeholders in urban China was worsening. Among these challenges the IRS faces, two are especially noteworthy - a decline in profits and increasing regulatory pressure from the government. In our analysis we primarily focus on the segment of the IRS that deals with collection and pre-processing (sorting, separating, cleaning, bulking, refurbishment, material extraction) of recyclables and Waste Electrical and Electronic Equipment (WEEE) in urban China. Our results indicate that despite their strong prevalence in this domain, informal actors are increasingly subjected to falling profit margins and regulatory pressure. However our results also shows that the IRS has in the past responded to both challenges rather effectively and thus may be able to maintain its presence in urban Chinese Waste Management (WM).
\end{abstract}

\section{INTRODUCTION}

From an economic perspective, the development of the People's Republic of China (PRC) is an extraordinary case: Between 1978 and 2011 the country achieved average GDP growth rates of around $10 \%$ (Taube, 2014) and thereby became the second largest economy in the world. However, this catching-up process has, especially in the last 20 years, generated high environmental costs and externalities that seriously challenge the country's environmental sustainability (He et al., 2012; Su et al., 2013). One of the problematic environmental consequences of this growth is the unprecedented increase in Municipal Solid Waste (MSW) in urban China. Between 1980 and 1998, annual MSW generation has nearly quadrupled from 31.3 million tons in the base year to 113 million tons in 1998 (Wang and Nie, 2001). In 2004, urban MSW quantities took another leap to 190 million tons (Chen et al., 2010) and in 2010 surpassed the benchmark of 200 million tons (Yang et al., 2013). This drastic development is more properly reflected in annual MSW growth rates: As there is no comprehensive data on waste quantities generated at the household level. The government and various research institutions merely present various 'guess-estimates'. These show that the annual MSW generation rate oscillated between $3-10 \%$ during the late 1990s up until the early 2000s (Wang and Nie, 2001).

In the last one and a half decades this rate increased to 6.5-10\% per year (Dorn et al., 2012; MEP, 2012). A similar tendency is exhibited in the growing generation of a new waste stream, WEEE, which has only in recent years exhibited a slight decrease in growth (see Figure 1).

In parallel to the challenge of growing waste quantities, China's waste management (WM) system features three interesting developments: Firstly, the government has tackled a long existent loophole as it began to establish its environmental legislation since the mid-1990s. Given that there have been few formal institutional structures to cope with environmental aspects before that time, the Chinese central government has exhibited a considerable effort in creating a comprehensive regulatory framework. Environmental protection, Cleaner Production, the Circular Economy (CE) and WM, which were not formally covered before that period (Steuer, 2016) have been gradually institutionalised since 2000. Secondly, the Chinese government has begun to re-build a formal, physical WM infrastructure since the late 1990s and early 2000s. Initially, Chinese municipalities had developed dense, public networks to collect and process MSW from industry and households. However this system
* Corresponding author:

Benjamin Steuer

email: benjamin.steuer@univie.ac.at
Detritus / Volume 04 - 2018 / pages 189-200

https://doi.org/10.31025/2611-4135/2018.13725

(c) 2018 Cisa Publisher. Open access article under CC BY-NC-ND license 


\section{Annual growth rates of MSW and WEEE in urban China}

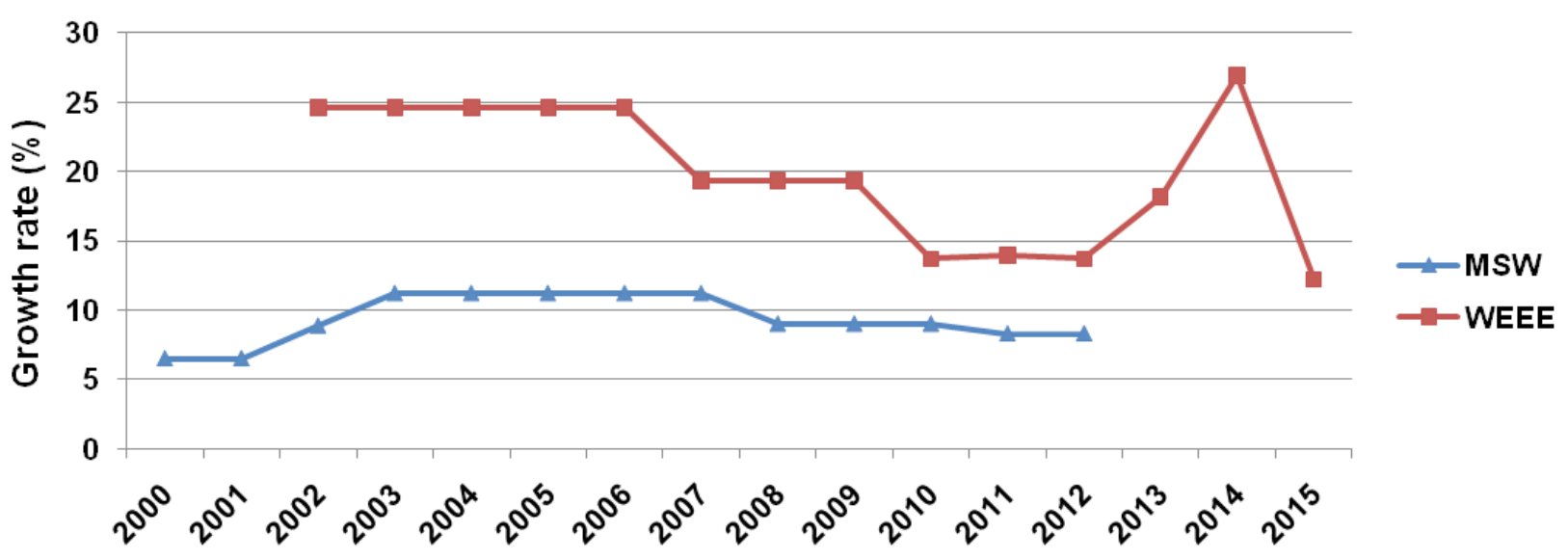

FIGURE 1: Annual growth rates for MSW and WEEE in urban China (Steuer et al., 2018).

fell victim to a politically initiated process of dismantling and reduction during the economic reforms of the 1980s: Formal, state-controlled MSW management was simply considered too cost intensive and strained too much of local budgets that focussed on fostering economic growth (Li, 2002; Fei et al., 2016; Steuer et al., 2017; Tong and Tao, 2016). The withdrawal of the formal sector generated an institutional leeway that directly coincided with, and in part, triggered the third major characteristic of in urban Chinese WM. Beginning with the late 1980s, a gradually growing migratory flow of rural labour entered the cities in search of work and also engaged in WM relevant activities. The emerging informal recycling sector (IRS) begun to engage in recyclable waste collection and pre-processing (sorting, separating, cleaning, bulking), as its stakeholders realised that they could commercialise these valuable secondary materials by selling them to manufacturing enterprises (Tong and Tao, 2016; Ensmenger et al., 2005; Steuer et al., 2015). Over time this new segment has established its own rule-based, organisation system and physical infrastructure, which has helped the IRS to achieve a strong informal dominance over the collection and pre-processing of waste recyclables and WEEE in urban China (Linzner and Salhofer, 2014; Steuer, 2016; Steuer et al., 2017).

Despite this story of success in the shadows of formality, recent macro-economic and WM developments in China have led to various difficulties for the IRS: Not only have informal incomes plummeted because of secondary resource price decreases over the last five years, but there are also indications that formal regulatory pressures have increasingly curtailed informal WM operations. Based on the findings of several research projects and field surveys on Chinese WM between 2013 and 2016 this paper deals addresses the question of whether the IRS in Chinese WM will be able to survive amidst this challenging environment. Our major findings are that the segment is extremely flexible and can adapt to changing demands by adjusting its institutional systems: Formal regulatory pressures induced the IRS to adapt their own collection and exchange practices. Secondly, we observe that the sector has achieved a level of maturity and service effectiveness, which not only benefits waste generating households, but also contributes to alleviating municipal budgets, as will be shown for the case of Beijing. Thirdly, recent economic changes indicate a slight recovery of domestic economic demand and thus increasing prices for secondary resources. If continued, this development may in turn reflect on the income levels of the IRS and thus sustain its operation.

\section{MATERIALS AND METHODS}

The present paper summarizes the result of several research projects: individual field investigations by $\mathrm{Mr}$ Steuer and a set of preceding publications of the authors (Linzner and Salhofer, 2014; Steuer et al., 2015; Steuer, 2016; Schulz and Steuer, 2017; Steuer et al., 2017; Steuer et al., 2018). The findings presented were primarily collected in the cities of Beijing and Guangzhou and supplemented by investigations in Shenzhen, Shanghai, Wuhan, Guiyu and the wider Guangdong area. During our research period over 250 structured and semi-structured interviews with stakeholders of the Chinese IRS were conducted. The intentions for doing so were twofold: First, the interviews aimed to determine and assess typical WM related particularities of the IRS, such as daily collected volumes ( $\mathrm{kg} / \mathrm{cap} / \mathrm{day})$, monthly income in Chinese Renminbi (RMB/cap/month) and related selling and buying prices of recyclables (RMB/ $\mathrm{kg}$ or unit). Second, the interview questions also addressed sources and exchange patterns of waste recyclables obtained by the IRS. In this regard, we intended to assess the sources of waste recyclable supply of the IRS, collection and exchange routes and habits of interaction. Preliminary results from earlier interviews have gradually helped to discern informal WM infrastructures, such as Trading Points (TPS) in Beijing (Steuer et al., 2017) or informal second hand markets for electronic devices in Beijing and Guangzhou (Steuer, 2016). These network-like connected markets and TPs have further served as reference points for our observations and interviews, so as to adequately capture the transaction intensity of waste recyclables by the IRS. In regard to waste streams, we primarily focussed on WEEE and recyclables (paper, cardboard, plastics, met- 
als, wood), because it is only these fractions that the IRS is interested in given their economic value. Finally, there is a need to mention the difficulties regarding the obtaining of data on this segment in urban China. Due to the IRS' informal nature available information is relatively sparse. The Chinese government itself does not offer any statistics on informal activities in WM. Moreover the subject itself is treated as politically sensitive since the IRS operates outside of the legal framework, offers only limited options for control by the state and is considered as an unwanted societal phenomenon (Steuer, 2016). Therefore this paper is also supplemented by earlier research on the subject matter, as well as by media reports, which often provide useful supplementary information on matters of income, size and collection quantities of the IRS.

\section{RESULTS}

\subsection{Size, collection quantities and income levels of the IRS}

With regards to assessing the dimension of the IRS, one of the most challenging tasks concerns the estimation of the sector's size. As noted in the Materials and Methods section, there are no comprehensive assessments for the Chinese case. Moreover, preceding estimations compiled by the authors vary considerably: from below two million in urban areas (Chen et al., 2010), to over 3.4-5.6 million (Linzer and Salhofer, 2014), up to as much as 18 million people (Gu et al., 2016) are documented to be active in informal WM in China. It must be presumed that these variations also originate in certain labour force fluctuations, determined by the recyclable market and respective demand for materials and collection services. Such fluctuations may be as high as 2 million people per year, which was the estimated increase in 2014 that has been presented by the central government (MOC, 2015). Our analysis for Beijing indicates a similar picture: Over the years, the numbers of informal actors have gradually increased, but not in a strict linear fashion (Table 1). Collected data are here again mostly guess-estimated figures presented by preceding research with the exception of the data set for 2013: In this year's research project we extrapolated informal actor sizes in Beijing by using informal waste markets (Trading Points) as a proxy for assessing informal actors' presence in Beijing. The numbers we extrapolated suggested that approximately $0.77 \%$ of Haidian's population are engaged in informal waste recovery. A bold extrapolation for entire Beijing thus indicated that the size of the IRS in the Chinese capital comprises approx. 150,000 individuals.

One of the key research tasks over recent years was to ascertain the collection capacities of the IRS regarding recyclables and WEEE. Generally we found that for both fractions of informal stakeholders have performed very effectively (Steuer et al., 2015; Steuer, 2016; Steuer et al.,
2017). For Beijing's communal recyclable waste, various estimations contend that the IRS in urban China achieves recovery rates ('Sum of recyclables collected' divided by 'sum of recyclables generated') of around 17-38\% (Linzner and Salhofer, 2014) or 20-40\% (Ensmenger et al., 2005). In absolute numbers this may amount to as much as 1-2 million tons of recyclables annually in Beijing (Ensmenger et al., 2005; Solidwaste, 2015). In our 2016 research project we went one step further and juxtaposed the quantities of recyclables generated at the household level with those collected by the IRS within one sub-district of urban Beijing. Based on interviews and waste quantity documentation of generators and collectors, it was revealed that the informal sector achieves a recovery rate for recyclables of around $90 \%$ (Steuer et al., 2018). However, here it has to be kept in mind that we only surveyed one of 22 sub-districts that are subordinated to the district of Haidian. These findings can therefore not be taken as a representative picture for the entire Beijing area.

For the case of WEEE, an analysis of various preceding studies shows that informal collection recovers around $60-80 \%$ of End-of-life (EOL) devices from households in urban China (Table 2), which generate the majority (approx. $70-80 \%$ ) of WEEE in urban China (Yang et al., 2008; Wang et al., 2011).

The effectiveness of informal collection becomes even more visible if juxtaposed to recovery rates of the formal system (Table 3 ). Despite an attempt to raise these quotas via a state initialised pilot project (the Old-for-New scheme $(\mathrm{OfN})$ ), formal collection still lags behind informal performance.

Here again it should be noted that the IRS plays a significant function in the context of the CE in two ways: firstly, a number of formal recycling companies $(n=12)$ interviewed in 2015 indicated that $90 \%$ of WEEE supplied to them, stem from informal channels (Steuer et al., 2015). Secondly, informal collectors primarily aim to sell recovered devices for refurbishment and repair at nearby second-hand markets for electronics (Steuer, 2016). The primary motivation for doing so is that informal stakeholders can reap a bigger profit from selling devices for reuse than from salvaging components or selling it to formal recycling. What needs to be kept in mind is that this practice is not formally forbidden, but it contravenes the state's effort, which is to promote WEEE recycling and material extraction via its wide network of formal recycling yards (Schulz and Steuer, 2017).

Despite these strong signals, interviews conducted by the authors between 2013 and 2016 have indicated that individual collection quantities ( $\mathrm{kg} / \mathrm{cap} / \mathrm{year}$ ) have gradually declined in recent years. Statements from informal stakeholders have revealed multiple factors that account for this development: (1) a lack of domestic demand for secondary raw materials associated with declining eco-

TABLE 1: Size of informal stakeholders in Beijing's WM (1998 - 2016) (Steuer et al., 2018).

\begin{tabular}{c:c:ccccccccc} 
Year & $\mathbf{1 9 9 8}$ & $\mathbf{2 0 0 0}$ & $\mathbf{2 0 0 9}$ & $\mathbf{2 0 1 0}$ & $\mathbf{2 0 1 1}$ & $\mathbf{2 0 1 2}$ & $\mathbf{2 0 1 3}$ & $\mathbf{2 0 1 6}$ \\
\hline $\begin{array}{c}\text { Number } \\
\text { (in 1,000) }\end{array}$ & 82 & 100 & 160 & 130 & $130-300$ & $140-186$ & $150-170$ & 160 \\
\hline
\end{tabular}


TABLE 2: Informal collection of WEEE from urban households in China (Steuer, 2016).

\begin{tabular}{|c|c|c|}
\hline $\begin{array}{c}\text { Informally collected WEEE (\% of } \\
\text { quantity generated } \\
\text { by urban households) }\end{array}$ & Area & $\begin{array}{c}\text { Year of } \\
\text { measurement }\end{array}$ \\
\hline 60.0 & China & 2011 \\
\hline 88.0 & China & 2011 \\
\hline 57.0 & Peking & 2005 \\
\hline 50.0 & Peking & 2005 \\
\hline 30.0 & Peking & 2008 \\
\hline 60.0 & Peking & 2010 \\
\hline 60.0 & Peking & 2011 \\
\hline 30.0 & Peking & 2012 \\
\hline 76.0 & Shanghai & 2013 \\
\hline 55.0 & Xi'an & 2010 \\
\hline 51.0 & Baoding & 2012 \\
\hline 50.0 & Hangzhou & 2013 \\
\hline 37.0 & Taizhou & 2009 \\
\hline 43.0 & Ningbo & 2003 \\
\hline
\end{tabular}

nomic growth in China; (2) increases in informal stakeholder numbers in urban areas have induced an increase in competition for recyclables and WEEE; (3) stronger efforts of the formal private sector to engage in material collection via online-based collection platforms (Steuer, 2016; Steuer et al., 2017 and 2017b).

The element of income constitutes the most decisive motivation for stakeholders to enter the IRS. Broadly speaking income opportunities for the IRS were comparatively high during the 1990s and 2000s and still maintained an attractive level above local minimum wages in the firstand-a-half decades after 2000 (Li, 2002; Ensmenger et al., 2005; Tong and Tao, 2016; Steuer et al., 2017). What can be gained from WM activities very much depends on the market prices for secondary materials, and these in turn are determined by the macro-economic demand for secondary resources. Moreover, the recent decline in China's GDP
TABLE 3: Recovery of WEEE by formal stakeholders (Steuer, 2016).

\begin{tabular}{l|c|c|c} 
WEEE received by & $\begin{array}{c}\text { Proportion } \\
\text { of recovered } \\
\text { WEEE (\%) }\end{array}$ & Area & $\begin{array}{c}\text { Year of } \\
\text { measurement }\end{array}$ \\
\hline Recovery and take & 14 & Taizhou & 2009 \\
back stations & 10 & Peking & 2010 \\
& 10 & Peking & 2011 \\
& 13 & Baoding & 2012 \\
\hline Return to retailers & 24 & Shanghai & 2013 \\
before the OfN (2009- & 16 & Ningbo & 2003 \\
11) & 14 & Peking & 2005 \\
\hdashline Return to retailers & Peking & 2005 \\
during the OfN (2009- & 7.8 & Xi'an & 2010 \\
11) & 20 & Peking & $2009-2011$ \\
& 20 & Peking & $2009-2010$ \\
\hline
\end{tabular}

growth also affects informal recyclable collection quantities and in turn derived incomes. Our two surveys in Beijing (2013 and 2016) revealed that informally recovered quantities ( $\mathrm{kg} / \mathrm{cap} /$ day) and respective incomes have plummeted rather drastically (see Table 4). To a significant degree this development can be attributed to the decrease in falling recyclable prices. Beyond that it needs to be mentioned that the surveys differed in terms of their spatial coverage: While the results of 2013 stem from interviews within eight sub-districts in Beijing, the 2016 survey was limited to one such sub-district. In a slightly related fashion, we also discerned that recyclable markets or TPs, where incomes for collecting parties (Waste Pickers and Waste Merchants) are generated, exhibit varying price offers for recyclables. Thus the 2016 survey may in fact have only captured those TPs that offer a comparatively weak profit margin for collecting stakeholders, which in turn might only improperly reflect actual profit realities.

Assessing informal incomes generated through collection and selling of WEEE is more difficult for the following reasons: As our interview partners have stated on several occasions there is no strict specialisation between stakeholders that only focus on recyclables or on WEEE. Rather the IRS collects what it can get. Secondly, the markets for informal WEEE exchange differ significantly in terms of prices paid and offered across various cities. Thirdly, dif-

TABLE 4: Prices (in Chinese RMB) \& recovered quantities of recyclables (metals, paper, plastics and cardboard) and income levels of the IRS in Beijing (Steuer et al., 2018).

\begin{tabular}{|c|c|c|c|c|}
\hline Category & Year & Waste Pickers & Waste Merchants & Middle Men \\
\hline \multirow{2}{*}{ Number of interviewees } & 2013 & 25 & 54 & 19 \\
\hline & 2016 & 31 & 29 & 16 \\
\hline \multirow{2}{*}{ Median collected quantity (kg/cap/day) } & 2013 & 16 & 311 & 890 \\
\hline & 2016 & 14 & 80 & 116 \\
\hline \multirow{2}{*}{ Median net income (RMB/ month) } & 2013 & 1,200 & 2,500 & 5,250 \\
\hline & 2016 & 650 & 3,000 & 2,000 \\
\hline \multirow{2}{*}{ Price of iron scrap (RMB/ ton) } & 2015 & & 1,600 & \\
\hline & 2016 & & 900 & \\
\hline \multirow{2}{*}{ Price of copper scrap (RMB/ ton) } & 2015 & & 38,000 & \\
\hline & 2016 & & 32,000 & \\
\hline \multirow{2}{*}{ Price of aluminium scrap (RMB/ ton) } & 2015 & & 10,300 & \\
\hline & 2016 & & 7,600 & \\
\hline
\end{tabular}


ferent recyclable categories reap different prices and that is especially reflected in preferences of the IRS for foreign brands vis-à-vis domestic ones. This aspect is related to different quantities of valuable components inside the devices, as well as to brand reputations influencing the resale potential of refurbished at second hand markets (Steuer et al., 2015; Steuer, 2016; Schulz and Steuer, 2017).

\subsection{Institutional systems of the IRS}

The first structural aspect that characterises the IRS in China as well as in the global domain (Wilson et al., 2006) is the high degree of internal organisation. Based on observations in different Chinese cities we identified three different groups that engage in different activities in informal recyclable collection (see Table 5): firstly, the group of Waste Pickers (WPs), who roam through the streets by foot and primarily screen waste bins in public and residential areas for recyclables. Given their limited collection capacity this group recovers smaller quantities than Waste Merchants (WMs), who focus on doorstep collection directly from households and who, due to the use of tricycles, can transfer collected recyclables over relatively wide distances. The third informal group are Middle Men (MM), who buy recyclables from the two collector groups and use trucks to transfer these materials to their private depots. There, MM pre-process the fractions (storing, cleaning, separation, and sorting, refurbishing, material extraction) and then sell these to manufacturers or recyclers (Steuer et al., 2017). Trading Points (TPS) as infrastructural nodes for exchange play a decisive role and will thus be discussed separately in the following paragraphs.

The collection service efficiency of the IRS is strongly dependent on how its stakeholders engage with the suppliers of recyclables, i.e. primarily households. In this regard, those persons in charge of recyclable and WEEE collection adopt a pro-active stance to connect and establish relationships with households. One practice is that WMs roam through residential quarters and offer their services through verbal announcements. Another often practiced way is that WMs set up cardboard signs in front of residential compounds, on which their mobile phone number and the recyclables or WEEE devices they collect are stated (Figure 2).

Moreover, many collectors also make use of business cards to connect to their customers. In this regard, interviewed WMs stated that good communication, i.e. ensuring the flow of information, is most decisive for increasing working efficiency: Arrangements via phone calls provide stakeholders with the flexibility to align collection time and routes with actual household demand (Li, 2002; Steuer et al., 2015). The core strategy behind this practice is that WMs pursue the development of a steady customer base and therefore mutual reliability and trust have to be fostered. For households the pivotal reason to cooperate with the IRS can be attributed to a particular value concept that Chinese households apply to recyclables and WEEE. In contrast to western societies, Chinese residents perceive discarded recyclables and EOL devices not as rubbish, but as a valuable resource that if sold can contribute to overall household income (Zhang and Wen, 2014). This stance explains why urban Chinese households exhibit a preference for those types of WM services that offer a pecuniary reward or compensation in exchange for waste recyclables. As a result Chinese households have expressed a strong preference for informal collection and relatively little interest for formal collection, which cannot or only in a reduced form offer monetary compensation for waste recyclables (Steuer et al., 2018).

At the level of physically manifested systems, the IRS has produced a highly innovative system, which is the aforementioned TPs (Steuer et al., 2017). These infrastructural nodes are of a mostly small and scattered nature, resembling small markets, which are composed of small booths and trucks with mobile ground scales. At these highly mobile points that are open for at least half a day recyclable- and WEEE-collecting stakeholders (residents, WPs, MM) convene and exchange materials for money. MM operate as buyers, who further process waste recyclables before transferring them to industry or recycling (Figure 3 ). The system itself combines elements of innovation as well as imitation: TPs are innovative in the sense that they are a bottom-up solution devised by informal stakeholders so as to overcome long transport distances. As we extrapolated in our 2013 study, Beijing's sub-district Haidian features a TP-to-resident proportion of around 0.87 TPs per 10,000 inhabitants. This particular spatial distribution of TPs thus facilitates collection and transfer activities of the involved stakeholders. At the same time however the TP system bears a strong resemblance (imitation) to the prior existing formal Supply and Marketing Cooperatives, which were established in Maoist China and which featured similar functions and density as the TPs. Thus the IRS appears to have re-innovated a former formal, effective system.

As for the aspect of WEEE collection and refurbishment the IRS has further developed an upgraded version of the TP system. At its centre are second-hand markets for refurbished and repaired electronic devices. These operate

TABLE 5: Informal stakeholder characteristics in urban Beijing MSW (Steuer et al., 2018).

\begin{tabular}{|c|c|c|c|}
\hline Stakeholder & Waste Pickers & Waste Merchants & Middle Men \\
\hline Means of transport & By foot & Tricycle & Truck \\
\hline Source of recyclables & $\begin{array}{c}\text { Public bins, bins in residential } \\
\text { quarters }\end{array}$ & Households (doorstep collection) & $\begin{array}{c}\text { Small enterprises, households, } \\
\text { Trading Points }\end{array}$ \\
\hline Waste management activity & Collection, selling at Trading Points & Collection, selling at Trading Points & $\begin{array}{c}\text { Buying at Trading Points, storage, } \\
\text { sorting cleaning, bailing material } \\
\text { extraction selling to industry or } \\
\text { recycling }\end{array}$ \\
\hline
\end{tabular}




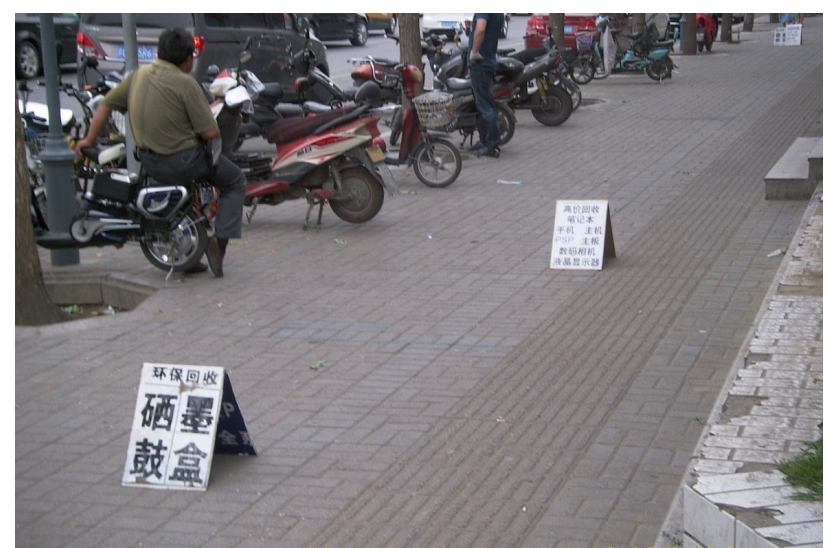

FIGURE 2: Cardboard signs of Waste Merchants in Beijing, Haidian district (@ Steuer, Ramusch and Salhofer, 2016).

under the premise that the collected devices still possess a certain reuse value and are thus not transferred to recycling by informal collectors. Here again, the decisive motivation for informal stakeholders to sell End-of-Life devices to second-hand markets for refurbishing and reuse is that the profits generated are higher than what is offered by formal or informal recyclers. The legal position of these markets is situated somewhere between the formal and the informal realm: In many markets investigated in Beijing and Guangzhou, sellers have, in most cases, obtained licenses for their operations. On the other hand, however, the refurbished devices often lack legal warranties and proper labelling (Steuer, 2016). The functionality of the markets itself is again very similar to the TPs (see Figure 4): households and businesses as generators of obsolete devices either directly exchange EOL electronics at markets for monetary compensation or they sell their obsolete devices to informal collectors, who then further transfer these to the markets. Another, third transfer channel, comes in the form of repair services. These are generally small shops that sell devices obtained from consumers to markets or in some cases they provide repair services directly to second-hand markets (see Figure 5). Finally, markets serve as suppliers of refurbished devices to households/ consumers, who are attracted by comparatively cheap second-hand electronics

As we alluded to above, the main purpose of second-hand markets is the generation of high profits for the IRS. Profit margins themselves are highly dependent on the device age and thus possible demand as well as the location of the markets itself: for example, in 2015, profit rates of $100 \%$ appeared to be quite common for 25 -inch TVs that were not older than 5 years. These profits however are also subject to the location of markets within the respective city: preliminary observations by Steuer and Schulz have indicated that the more second-hand markets are located at the outskirts of city centres, the lower the profit margin will turn out (Steuer, 2016).

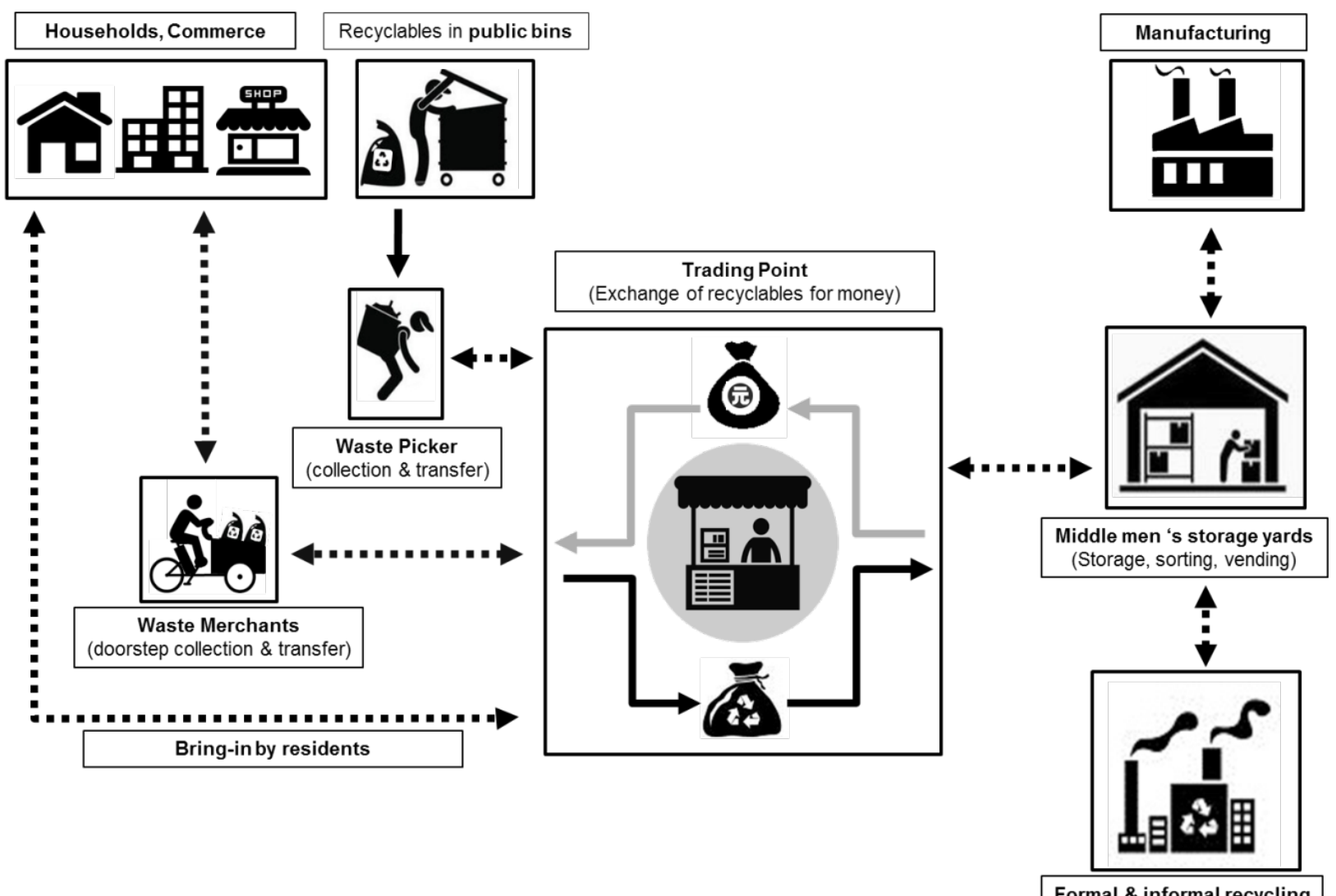

FIGURE 3: The connective function of Trading Points [Grey arrows indicate monetary flows, black arrows refer to recyclable flows and two-directional arrows indicate the exchange of money for recyclables] (Steuer et al., 2017). 


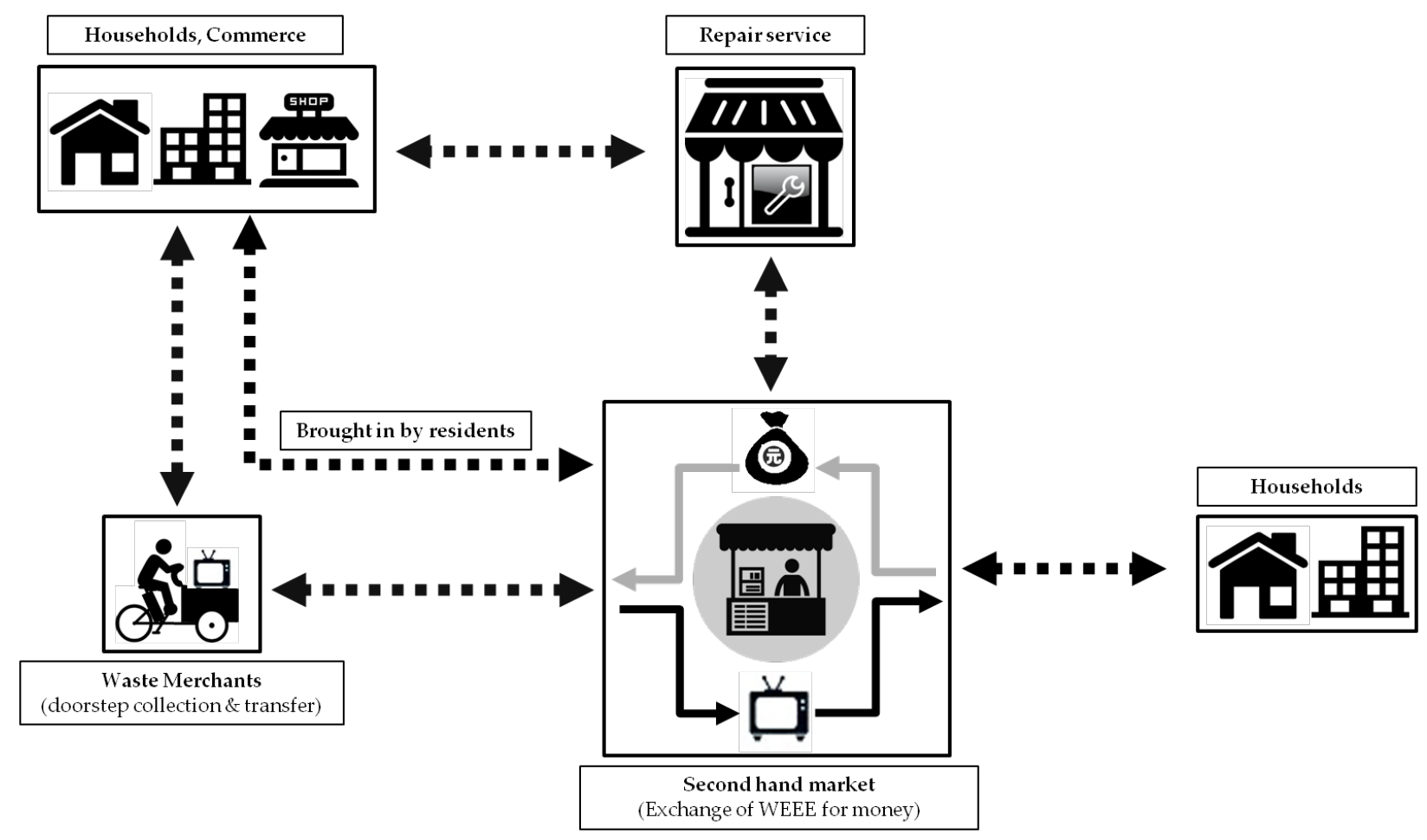

FIGURE 4: WEEE transfers for reuse via second-hand markets (Grey arrows indicate monetary flows, black ones represent WEEE flows and two-directional arrows indicate the exchange of money for WEEE) (Steuer, 2016).

\subsection{Challenge 1: declining profits for recovered recy- clables and WEEE}

Despite the evidence of the IRS' effective performance there are still some challenges confronting informal stakeholders in WM. The first problem relates to the decline in profits for recovered recyclables and WEEE. Via several interviews conducted in 2016, informal stakeholders have repeatedly stated that market demand for recyclables has significantly decreased since 2014 (Steuer et al., 2018).
These perceptions are mirrored by China's online recyclable price indices: between 2015 and 2016, the values of secondary copper, aluminium and iron decreased by $16 \%$, $26 \%$ and $44 \%$ respectively (CRRA, 2017). Such deterioration of prices, according to the interviewees, has affected all recyclable fractions except for paper and cardboard, which in turn has led to some negligence in the informal collection of the less valuable recyclables. More importantly for the IRS however is the influence of these declines on
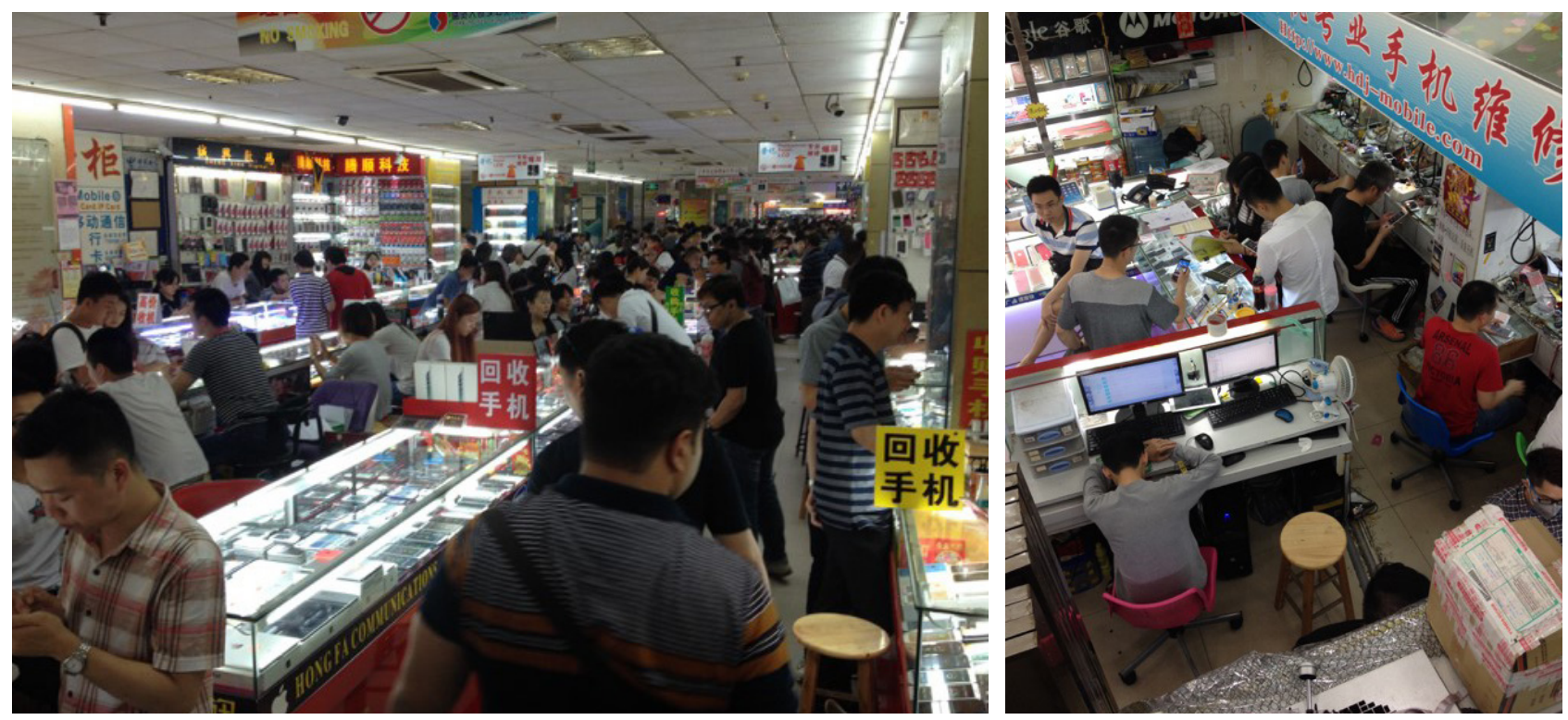

FIGURE 5: Guangzhou's Dashatou second-hand market with (a) trading area and (b) integrated repair service structures (ㄷ Yvan Schulz). 
the incomes of stakeholders (see Table 4). This situation has been further aggravated by the fact that competition between stakeholders has increased due to a continuously growing influx of newcomers in the sector. In this regard, the China Ministry of Commerce has estimated that there were about 2 million new persons entering the IRS in 2014 alone (MOC, 2015). Both factors have led to lower overall incomes given lower collection quantities ( $\mathrm{kg} / \mathrm{cap} /$ day) resulting from stronger competition and lower recyclable prices. Nevertheless, both factors may have no effect on overall recyclable and WEEE collection dominance of the IRS as higher stakeholder numbers may still recover the daily generated recyclable quantities.

The challenge of declining profits also extends to the informal WEEE refurbishment and trading. Here however, the impetus comes from a slightly different angle. On the one hand, households as primary generators of WEEE in urban China have increasingly realised the potential economic value of these EOL devices. By implication, this makes it harder for the IRS to achieve a good profit from this first instance of transaction. Moreover, decreases in profits originate in changes at the second step of transaction: the markets themselves, at least those observed in Beijing and Guangzhou, have undergone a gradual process of government-induced formalisation. Measures implemented over recent years aimed to formalise the processes of refurbishment and resale, i.e. via the issuance of obligatory service guarantees offered to customers, billing and invoice requirements as well as increasing documentation requirements. Interviewed traders have stated that such measures have indeed affected their profits to the point that some saw leaving this business as the final option (Steuer, 2016). In Guangdong province's Guiyu town, second hand markets for electronic components were even regulated to such a degree that trading stalls were empty during our visits. The reason for such, local traders stated, was that salvaged component prices were too high. This in turn was a result of various fees imposed on traders by the local government, which were then translated into higher component prices. In response to the question as to why the traders had entered the market, they explained that the local government had confronted them with the choice to either to integrate and resettle within the industrial park's market, or to close down their operations (Steuer, 2016).

\subsection{Challenge 2: formal regulatory measures against the IRS}

The strong and lasting dominance of informal actors in urban WM has quite instinctively lead municipal governments to respond. After having withdrawn from WM in the early 1980s and thus leaving the field open to informal engagement (Li, 2002; Fei et al., 2016; Tong and Tao, 2016), the state returned in the mid-1990s by establishing a formal institutional structure to tackle the challenge of urban waste. Despite the fact that the centrally issued, major legislative pieces such as the law on solid waste left the aspect of collection relatively undefined, municipal governments addressed collection and also attempted to manage respective activities by the IRS. What is shown in these rather general legislative pieces of municipal governance is that local governments have predominately adopted a prohibitive stance against the IRS (Figure 6). Among the measures, prohibitive ones primarily aim to expel informal WM activities from public places, while integrative approaches include organisation under, and cooperation with, official authorities.

The implication of these measures is manifested in daily practises of local governance. In regard to the prohibitive measures, the aim is to set up alternative, formal structures. In regards to this aspect, informal interviewees indicated that TPs are more often subject to control and monitoring, which often forces stakeholders to suspend their

\section{Local government regulations on informal stakeholders in WM}

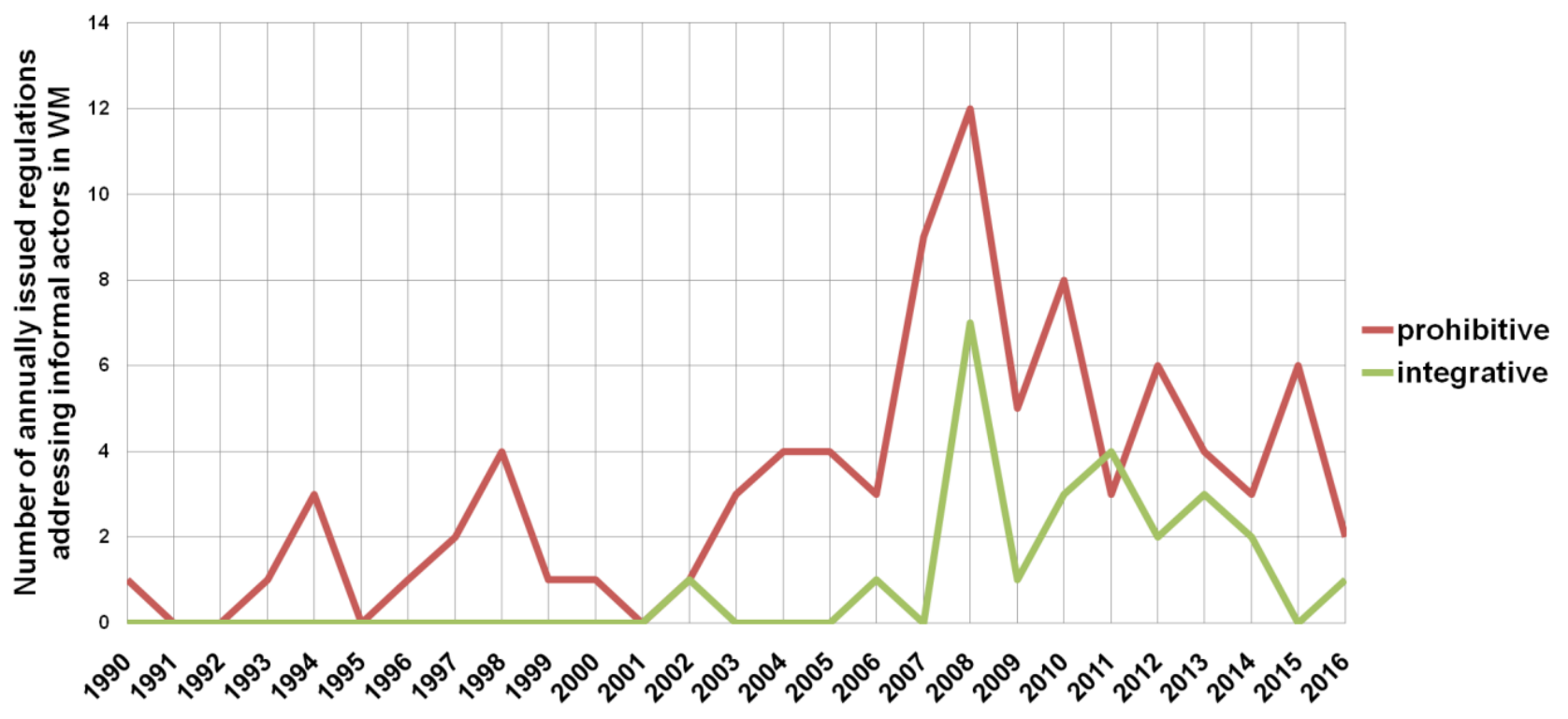

FIGURE 6: Local regulations on the informal sector in urban China (Steuer et al., 2018). 
operations. Second hand markets are, as mentioned above, increasingly confronted with the necessity to formalise. At the next higher level, the so-called 'waste villages' that are situated in the outskirts of cities such as Beijing's Dongxiaokou, are increasingly forced to relocate. All of these measures affect the operation of the IRS. Moreover, local governments have since the 2000s implemented pilot programs that aim to set up a parallel formal waste collection system. Formal collection stations have been established within residential quarters so as to directly channel waste recyclables into the formal system. In Beijing alone the number of these booths has been gradually growing and as of 2014 stands at 4,400 units (Zhang and Wen, 2014). Quite clearly the overarching objective of this step is to establish the link between generators and the formal WM system, while the IRS should simultaneously be cut off from access to waste recyclables and WEEE. In regards to the integrative approaches adopted by local governments, the general idea is to incorporate the IRS within the formal framework e.g. via the issuance of licenses and a top-down organisation via the municipal government. Such efforts were however met with rejection by the IRS, which perceived this approach as highly negative due to the high cost burdens that officials demanded for the licensing process (China. com, 2007; Chen at al., 2010; Zhou, 2010).

\section{DISCUSSION}

We have presented an overview on the status-quo of the IRS in China together with two significant challenges that it faces. The first of these two, i.e. the aspect of prices, is relatively simple as it is primarily a question of domestic demand for secondary resources. Given the decline in prices in 2014-2015, informal stakeholders, especially MM, have resorted to stockpiling recovered recyclables and waiting until prices recover (Cnenergy, 2016). There is a good reason for adopting this 'wait-and-see' strategy. Firstly, the IRS, especially in Beijing, has in its past already been confronted with a similar situation. In 2006 and 2008 the sector was faced with a decline in secondary raw material price declines. In both instances, the IRS managed to survive and adapt to the changing environment. In both instances, lower incomes were accepted by those who remained in business, while others simply abandoned the sector (Chinadigitaltimes, 2016; Sina Finance, 2006). Secondly, recent macro-economic developments hint at a recovery of domestic demand among manufacturing and export oriented industries (SCMP, 2016a and 2016b), which apparently induced a rise in secondary raw material prices in late 2017 (CRRA, 2017). Thus, the challenge of declining profits in the IRS might be regarded as a typical example of a temporarily limited business cycle. This in turn leads to the assumption that the existence of the IRS in waste recyclable collection might be safeguarded in the near future. What is more difficult to assess are the future profit challenges associated with informal WEEE management. Whereas profits from informally collected WEEE that goes to recycling is equally subject to secondary raw material demand, the story is slightly different for EOL devices that are sent to second hand markets because the informal value chain is dependent on consumer preference constellations. While refurbished electronics were especially appreciated by urban consumers in the 1990s and 2000s, the gradual growth of the middle class in urban areas has changed this trend (Steuer, 2016). These consumers are now increasingly looking for high quality products, which leads to second hand goods being increasingly sold to consumers with lower income. It is quite likely that this will also lead to a decline in profits for second-hand, refurbished devices. In summary, we assume that there is a higher potential for these parts of the IRS that engage in waste recyclable collection than for those that deal with WEEE collection and refurbishment.

The second major challenge relates to the increasing rigidity of formal regulations. Initially, the IRS in recyclable and WEEE collection could only emerge because of the decline of formal WM structures. The response of the central government to issue a set of regulatory measures has been ambitious. For example, the collection of recyclables and WEEE has been absolutely ignored in key laws and regulations (Steuer et al., 2015; Steuer et al., 2018; Schulz and Steuer, 2017). In a slightly more ambitious fashion, there have been a few, tentative ad hoc measures to formalise second hand markets for repaired electronic devices. Despite these measures the IRS is yet able to continue its operation in this field (Steuer, 2016). Moreover, those regulations at the local level that directly address the IRS in collection primarily employ a prohibitive approach to confront the segment. Given the historical development in urban Chinese WM, this strategy might however be prone to fail as it ignores the lessons from the dynamic relationship between the formal and informal sector. In various urban areas the attempts to crack down on the IRS have only resulted in evasive measures of its stakeholders, who respond by resettling or transferring their businesses to nearby areas or simply become more vigilant towards formal controls (Steuer, 2016; Tong and Tao, 2016; Goldstein, 2017). In an attempt to replace informal collection the Beijing municipal government, among other major cities, initiated a pilot project in 2000, which aimed at establishing recyclable and WEEE collection booths within residential quarters. This was done to cut the IRS out of recyclable collection from households. However there were some flaws in the implementation of this otherwise cunning concept: firstly these depots offer less money to households for their recyclables than the IRS does. Secondly, the operators of these booths are mostly former informal stakeholders, who took this low paid position (1,500RMB/ month) (FON, 2013) that ordinary Beijing residents would refuse to take (Wang et al., 2008; Tong and Tao, 2016). Given that these operators still have good contacts to the IRS, they tend to resell these now formally collected recyclables back to the informal sector. Therefore the historical development (see Figure 7) between the activities of the formal (left section in the picture) and the informal system (right section in the picture) can be seen as a dynamic, reciprocal relationship in which the IRS has continuously contravened and reacted to formal regulations and measures over time. This is not to say that formal regulations are entirely ineffective. Rather the IRS has developed a strong flexibility to cope with and adapt to formal measures. 
What needs to be discussed in this regard is that despite all the problems informal collection might cause for the formal system, it simultaneously creates an immense benefit for municipal WM budgets. Again, the case of Beijing offers a suitable example to explain this matter: in 1998, Beijing allocated 750 million RMB out of its budget to managing MSW. At the same time the IRS achieved a profit of around 1.1 billion RMB (Ensmenger et al., 2005). In regards to how much the performance of the IRS alleviates official WM expenditures data for the years 2010 and 2014 are particularly instructive: in 2010, Chinese experts estimated that practices of the IRS helped to save 400 million RMB in annual official expenditures on WM (Solidwaste, 2010). This may be explained by two factors: firstly, in Chinese WM, the most cost intensive item is personnel costs, which in some municipalities range around $55-70 \%$ of total WM expenditures (Ren and $\mathrm{Hu}, 2014$ ). Given that the IRS dominates the labour-intensive collection operations, any abolishment of the sector would not only transfer this task to formal services and thus increase formal overall expenditures. The formal sector would also have to establish the as of now lacking processing and transfer structures for securing the potential gains from waste recyclable recovery.

The contribution of the IRS further increased in 2014: in this year Beijing's annual waste treatment costs amounted to 2 billion RMB (in 2014), while the services of the IRS simultaneously alleviated the municipal budget by approximately 1.8 billion RMB (Crrainfo, 2014). By implication, dispersing the IRS and substituting it's services would in turn force the municipal government to double its WM expenditures (see Table 6). If this cost-benefit element is juxtaposed to the larger perspective of the formal-informal dynamic in waste collection, one may understand why the Chinese government has not yet fully prohibited the IRS: it simply appears that the government intends to make use of this segment as long as possible to indirectly benefit from its contributions, while it simultaneously attempts to build up a formal system via pilot programs so as to substitute the informal sector on the long term.

\section{CONCLUSIONS}

In conclusion, the IRS in urban China is facing a variety of challenges, which have arguably worsened the working conditions of its stakeholders. These factors stem from domestic market volatility as well as from increasing regulatory efforts by the Chinese government. Both challenges do in fact affect the IRS but may not threaten its existence on the long term. Especially with regards to the second challenge it appears quite startling that despite many years of attempted curtailment the Chinese government still holds on to prohibitive measures to control the sector. This not only runs contrary to the Chinese domestic experience and the growing numbers of the IRS over the years. It also appears to neglect the experiences of other low- to middle-income countries like the Philippines or Brazil, where informal stakeholders have been integrated into the formal WM system (Steuer, 2016). Given the flexibility and proactive response of the IRS to formal measures, this prohibitive regulatory stance might be prone to fail. Therefore it might in fact be the first challenge that

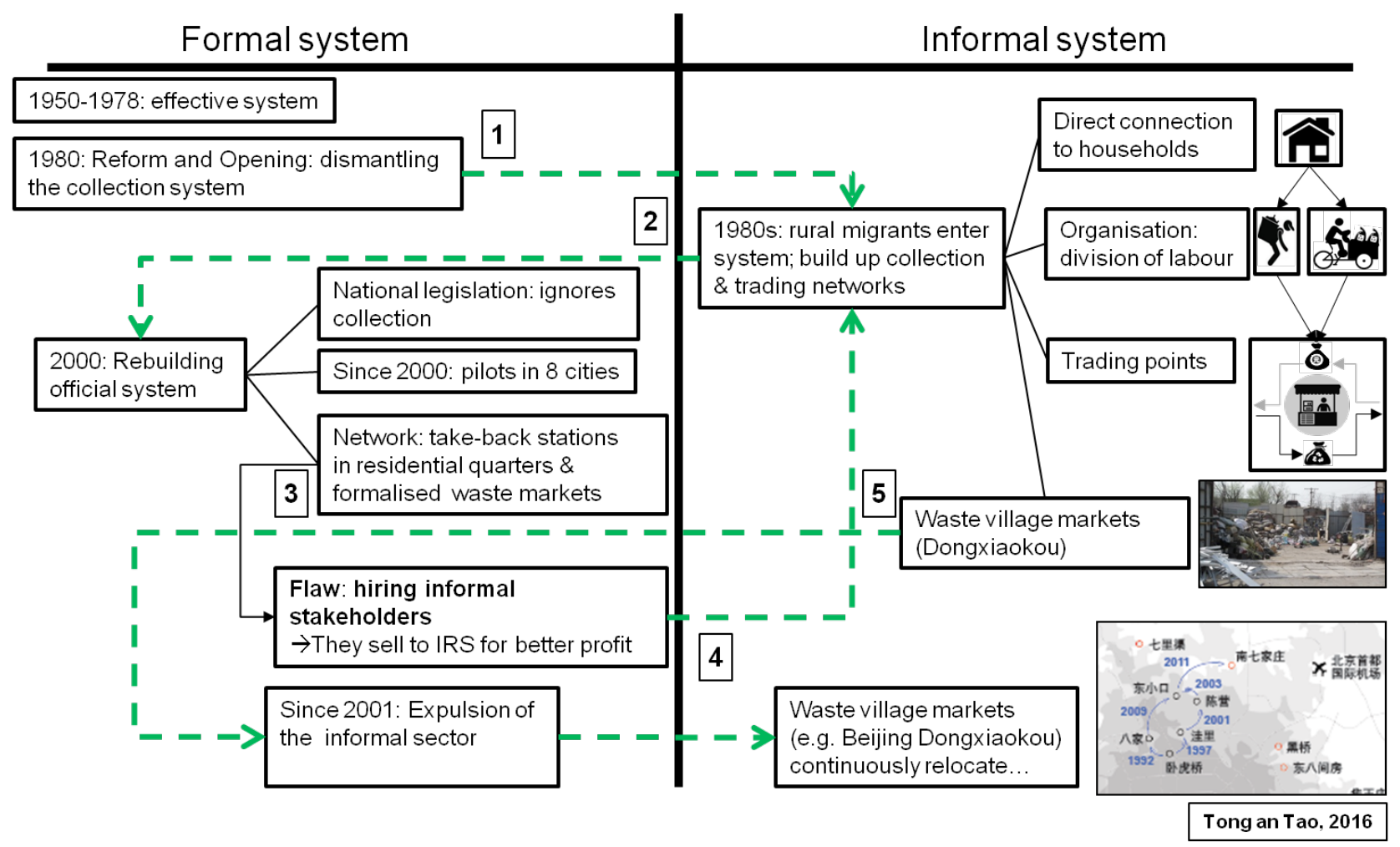

FIGURE 7: The interdependent evolution of the formal and informal systems in Beijing's WM: Responsive actions of each domain are indicated by green arrows connecting the action of one side with the response of the opposite side (Steuer et al., 2018). 
TABLE 6: Municipal budget expenditures on WM and respective cost savings of the IRS in Beijing.

\begin{tabular}{c|c|c|c} 
Year & $\begin{array}{c}\text { Expenditures on WM } \\
\text { (in million RMB) }\end{array}$ & $\begin{array}{c}\text { Performance of the IRS: } \\
\text { Cost saving for municipal budget } \\
\text { (in million RMB) }\end{array}$ & $\begin{array}{c}\text { Additional wM expenditures } \\
\text { without IRS } \\
\text { (in million RMB) }\end{array}$ \\
\hline 2010 & n.a. & 400 & n.a. +400 \\
\hline 2014 & 2,000 & 1,800 & 3,800 \\
\hline
\end{tabular}

can exert the biggest pressure on the segment. Should these stakeholders face continuously decreasing income opportunities over longer periods, then the sector will eventually begin to dissipate. Based on our observations, we assume that this development will not occur. Nevertheless, anecdotal evidence has indicated that incomes in this field have slowly, but gradually gone down over the last two decades.

\section{CONFLICT OF INTEREST}

The authors hereby state that there is no conflict of interest in regard to the publication of this paper.

\section{ACKNOWLEDGEMENTS}

The research for this paper was supported by: [1] the SWITCH-Asia Programme ['Improving resource efficiency for the production and recycling of electronic production by adoption of waste tracking system [REWIN)', [2] the Funds of the Austrian Central Bank ['Invisible hands? - Informal employment in the service of resource efficiency in urban China', Anniversary Fund, project number: 15325; and 'Invisible Markets - The Role of Households and Waste Collectors for Resource Management in Urban China, Beijing', Anniversary Fund, project number: 16763).

\section{REFERENCES}

Chen X., Geng Y., Fujita T. (2010) An overview of municipal solid waste management in China. Waste. Manage. 30, 716-724. Doi: 10.1016/j.wasman.2009.10.011

China.com. 2007. Waste Pickers 'turn formal': Are 660 Yuan of management fees turning into a source for illegal wealth accumulation by the government? (in Chinese). Online: http://www.china.com. cn/city/txt/2007-08/30/content_8771560_2.htm (accessed 16 February 2018).

Chinadigitaltimes (2016). 20 years of waste picking in Beijing: your capital city, my waste capital. Online: http://chinadigitaltimes.net/ chinese/2016/09/端传媒-北京拾荒20年：你的京城，我的废都/ (Accessed 14 October 2016).

Cnenergy (2016). China's millions of Waste Pickers suddenly disappear. Online: http://www.cnenergy.org/hb/201609/t20160912_376697. html (Accessed 18 August 2016).

CRRA (China Resource Recycling Association) (2017). Various search results. Online: http://www.crra.org.cn (Accessed 15 February 2017).

Crrainfo (2014). Why does waste separation in China meet so many difficulties? Online: http://www.crrainfo.org/content-19-18902-1. html (Accessed 5 April 2015).

Dorn T., Nelles M., Flamme S., Cai J. (2012). Waste disposal technology transfer matching requirement clusters for waste disposal facilities in China. Waste. Manage. 32, 2177-2184. Doi: http://dx.doi. org/10.1016/j.wasman.2012.05.038

Ensmenger D., Goldstein J., Mack R. (2005). Talking trash: an examination of recycling and solid waste management policies, economies, and practices in Beijing. E. W. Conn., vol. 1, n.5. Online: https://www. thefreelibrary.com/Talking+trash\%3A+an+examination+of+recycling+and+solid+waste+management...-a0159494046. (Accessed 15 January 2016)
Fei F., Qu L., Wen Z., Xue Y., Zhang H. (2016). How to integrate the informal recycling system into municipal solid waste management in developing countries: Based on a China's case in Suzhou urban area. Resour. Conserv. Recy., 110, 74-86. Doi: http://dx.doi. org/10.1016/j.resconrec.2016.03.019.

FON (Friends of Nature) (2013). Research Report On Waste Separation Pilot Areas in Beijing in 2012 (in Chinese). Online: www.fon.org. cn/uploads/attachment/17641370277681.pdf (Accessed 30 April 2016).

Goldstein, J. (2017). A Pyrrhic Victory? The Limits to the Successful Crackdown on Informal-Sector Plastics Recycling in Wenan County, China. Mod. China., vol. 43, n.1, 3-35. Doi: $10.1177 / 0097700416645882$.

Gu, Y., Wu, Y., Xu, M., Wang, H., Zuo, T. (2016). The stability and profitability of the informal WEEE collector in developing countries: A case study of China. Resour. Conserv. Rec., 107, 18-26. Doi: http:// dx.doi.org/10.1016/j.resconrec.2015.12.004.

He, G., Lu, Y., Mol, A., Beckers, T. 2012. Changes and challenges: China's environmental management in transition. Environmental Development, vol.3, pp. 25-38. Doi: https://doi.org/10.1016/j. envdev.2012.05.005

Li S. (2002). Junk-buyers as the linkage between waste sources and redemption depots in urban China: the case of Wuhan. Resour. Conserv. Rec., 36, 319-335. Doi:10.1016/S09213449(02)00054-X

Linzner R. and Salhofer S. (2014). Municipal solid waste recycling and the significance of 838 informal sector in urban China. Waste. Manage. Res., vol. 32, n. 9, 896-907. Doi: 839 http://dx. doi.org/10.1177/0734242X14543555.Ministry of Environmental Protection of China (MEP) and others (2012). Special program of the 12th five-year plan for waste recycling technology projects (in Chinese). Online: http://www.chinaero.com.cn/rdzt/sewghzt/ hygh/2012/08/125356.shtml. Accessed 12 March 2015

MOC (China Ministry of Commerce) (2015). Report on the development of China's renewable resource recovery industry (2015). Online: http://www.gepresearch.com/99/view-183128-1.html (Accessed 10 April 2017).

Ren X. and Hu S. (2014). Cost recovery of municipal solid waste management in small cities of inland China. Waste. Manage. Res., vol. 32, n. 4, 340-347. Doi: 10.1177/0734242X14526771.

Schulz Y. and Steuer B. (2017). Dealing with discarded e-devices. In Routledge Handbook of China's Environmental Policy: Sternfeld (ed.), Routledge, London, 314-329.

SCMP (South China Morning Post) (2016a). China's growth stabilises, but dangers loom, say economists. Online: http://www.scmp. com/news/china/economy/article/2072283/chinas-growth-stabilises-dangers-loom-say-economists (Accessed 20 February 2016)

SCMP (South China Morning Post) (2016b). China's growth stabilises but dangers loom, say economists. China's export machine powers ahead in January despite Trump threats. Online: http://www. scmp.com/news/china/economy/article/2069800/china-exportmachine-powers-ahead-january-despite-trump-threats (Accessed 20 February 2016)

Sina Finance (2006). Investigative report on the big army of 300,000 Waste Pickers: Beijing's Waste Pickers pick away 3 billion per year (in Chinese). Online: http://finance.sina.com.cn/leadership/ crz/20060206/06502317994.shtml (Accessed 20 January 2016) Solidwaste. 2010. Wang Weiping: 11 years of research on the Waste Picker groups (in Chinese). Online: http://news.solidwaste. com.cn/view/id_30515 (Accessed 20 March 2015).

Steuer B (2016). What institutional dynamics guide WEEE refurbishment and reuse in urban China? Recycl., vol. 1, n. 2, 286-310. Doi:10.3390/recycling1020286.

Steuer B., Ramusch R., Part F., Salhofer S. (2017). Analysis of the value chain and network structure in informal waste recycling in Beijing, China. Resour. Conserv. Recy., vol.117(B), 137-150. Doi: http://dx. doi.org/10.1016/j.resconrec.2016.11.007 
Steuer B., Ramusch R., Salhofer S. (2018). Can Beijing's informal waste recycling sector survive amidst worsening circumstances? Resour. Conserv. Recy., (under review).

Steuer B., Salhofer S., Linzner R. (2015). The winner takes it all - why is informal waste collection in urban china successful? In Sardinia 2015, Fifteenth International Waste Management and Landfill Symposium: Cossu et al. (Eds.).

Su, B., Heshmati, A., Geng., Y., Yu, X. 2013. A review of the circular economy in China: moving from rhetoric to implementation. Journal of Cleaner Production, vol. 42, pp. 215-227. Doi: 10.1016/j.jclepro.2012.11.020

Taube M. (2014). Grundzüge der wirtschaftlichen Entwicklung und ihre ordnungspolitischen Leitbilder in der VR China seit 1949. Duisburg Working Papers on East Asian Studies, No. 96/2014, 1-28. Online: https://www.uni-due.de/in-east_former_website/fileadmin/publications/gruen/paper96-2014.pdf. (Accessed 1 January 2015).

Tong X. and Tao D. (2016). The rise and fall of a "waste city" in the construction of an "urban circular economic system": The changing landscape of waste in Beijing. Resour. Conserv. Recy., 107, 10-17. Doi:10.1016/j.resconrec.2015.12.003.

Wang H. and Nie Y. (2001). Municipal Solid Waste Characteristics and Management in China. Japca J Air Waste Ma, vol. 51, n. 2, 250263. Doi: 10.1080/10473289.2001.10464266
Wang J., Han L., Li S. (2008). The collection system for residential recyclables in communities in Haidian District, Beijing: A possible approach for China recycling. Wast. Manage., 28, 1672-1680. Doi: http://dx.doi.org/10.1016/j.wasman.2007.05.020

Wang Z, Zhang B., Yin J., Zhang X. (2011). Willingness and behavior towards e-waste recycling for residents in Beijing city, China. J. Clean. Prod., 19, 977-984. doi:10.1016/j.jclepro.2010.09.016.

Wilson D. C. Costas V., Cheeseman R. C. (2006). Role of Informal Sector Recycling in Waste Management in Developing Countries. Habitat Int., 30, 797-808, doi: 10.1016/j.habitatint.2005.09.005.

Yang R., Zhu H., Chen Q. (2013). Project report of Shanghai's YHZC waste material recovery convenience services company (in Chinese). Available online: http://wenku.baidu.com/view/823ec6f589eb172ded63b743.html. (Accessed 7 July 2015)

Yang J., Lu B., Xu C. (2008). WEEE flow and mitigating measures in China. Wast. Manage., 28, 1589-1597, doi:10.1016/j.wasman.2007.08.019.

Zhang H. and Wen Z. (2014). The consumption and recycling collection system of PET bottles: A case study of Beijing, China. Wast. Manage. Res., vol. 34, n. 6, 687-698. Doi: http://dx.doi.org/10.1016/j. wasman.2013.07.015

Zhou, X. 2010. Understanding urban waste separation and collection from the government's handling of Waste Pickers (in Chinese). Online: http://www.cn-hw.net/html/31/201305/39702.html (accessed 23 June 2016) 